\title{
On the Precursory Abnormal Animal Behavior and Electromagnetic Effects for the Kobe Earthquake (M 6) on April 12, 2013
}

\author{
Masashi Hayakawa ${ }^{1,2^{*}}$, Hiroyuki Yamauchi3, Nobuyo Ohtani' ${ }^{3}$, Mitsuaki Ohta4, \\ Susumu Tosa ${ }^{5}$, Tomokazu Asano', Alexander Schekotov6, Jun Izutsu', \\ Stelios M. Potirakis ${ }^{8}$, Konstantinos Eftaxias ${ }^{9}$ \\ ${ }^{1}$ Hayakawa Institute of Seismo Electromagnetics Co. Ltd., UEC (University of Electro-Communications) \\ Incubation Center, Chofu, Japan \\ ${ }^{2}$ UEC, Advanced Wireless \& Communications Research Center, Chofu, Japan \\ ${ }^{3}$ Department of Animal Science and Biotechnology, Azabu University, Sagamihara, Japan \\ ${ }^{4}$ Department of Human and Animal-Plant Relationships, Tokyo University of Agriculture, Atsugi, Japan \\ ${ }^{5}$ Kagawa Prefecture Livestock Experiment Station, Kida, Japan \\ ${ }^{6}$ Institute of Physics of the Earth, Russian Academy of Sciences, Moscow, Russia \\ ${ }^{7}$ Department of Electronic Engineering, Chubu University, Kasugai, Japan \\ ${ }^{8}$ Department of Electronics Engineering, Piraeus University of Applied Sciences (TEl of Piraeus), \\ Athens, Greece \\ ${ }^{9}$ Department of Physics, University of Athens, Athens, Greece \\ Email: "hayakawa@hi-seismo-em.jp, hiroyuki.yamauchi19@gmail.com,mo205684@nodai.ac.jp, \\ ph8352@pref.kagawa.Ig.jp, sasha.schekotov@gmail.com, spoti@teipir.gr, ceftax@phys.uoa.gr
}

Received 5 July 2016; accepted 2 August 2016; published 5 August 2016

Copyright (C) 2016 by authors and Scientific Research Publishing Inc.

This work is licensed under the Creative Commons Attribution International License (CC BY). http://creativecommons.org/licenses/by/4.0/

\section{c) (i) Open Access}

\section{Abstract}

After the 2011 Tohoku earthquake (EQ), there have been numerous aftershocks in the eastern and Pacific Ocean of Japan, but EQs are still rare in the western part of Japan. In this situation a relatively large (magnitude (M) 6) EQ happened on April 12 (UT), 2013 at a place close to the former 1995 Kobe EQ (M 7), so we have tried to find whether there existed any precursors to this EQ, especially abnormal animal behavior (milk yield of cows), observed at Kagawa, Shikoku, near the EQ epicenter. The milk yield of cows has been continuously monitored at Kagawa, and it is found that the milk yield exhibited an abnormal depletion about 10 days before the EQ. This behavior has been extensively compared with the former electromagnetic precursors (ULF radiation, ionos-

\footnotetext{
${ }^{*}$ Corresponding author.
}

How to cite this paper: Hayakawa, M., et al. (2016) On the Precursory Abnormal Animal Behavior and Electromagnetic Effects for the Kobe Earthquake (M 6) on April 12, 2013. Open Journal of Earthquake Research, 5, 165-171. 
pheric perturbation). This leads to the discussion on the sensory mechanism of unusual behavior of mild yield of cows, and it may be suggested that ULF radiation among different electromagnetic precursors is a mostly likely driver, at least, for this EQ.

\title{
Keywords
}

\author{
Abnormal Animal Behavior, Earthquakes, Milk Yield of Cows, ULF Radiation, \\ Sensory Mechanism of Animals
}

\section{Introduction}

The prediction of an earthquake (EQ) (to be more exact, short-term EQ prediction) requires the presence of precursors of any kind [1], so that there have been carried out a lot of extensive studies on pre-seismic parameters during the last few decades (see, e.g., [2]). These precursors include, (i) mechanical, (ii) electromagnetic effects, and (iii) macroscopic phenomena [2]. Mechanical effects include foreshock activity, pre-slip effect etc. [2]. As for the second electromagnetic effect, it is recently agreed that electromagnetic phenomena do occur preceding EQs (e.g., [3]-[8]), which are considered to be very promising for short-time EQ prediction. Among various electromagnetic precursors, there are a few phenomena which are already found to be statistically correlated with EQs. One typical example is ionospheric perturbations, not only in the lower ionosphere using subionospheric VLF/LF (very low frequency/low frequency) propagation anomalies [9] and but also in the upper F region using bottomside sounding anomalies [10]. Furthermore, seismogenic ULF emissions have been observed prior to an EQ (e.g., [11]-[13]).

The third topic is macroscopic phenomena, which are mainly abnormal animal behavior [2]. The unusual behavior of dogs and cats includes barking loudly or being panicked in dogs, and hiding being restless etc. for cats. Many other examples are described in the literature ([2] [14]-[24]), together with the suggestion of possible sensory mechanisms of such abnormal animal behavior.

However, most of previous works on macroscopic phenomena were based on the anecdotal reports or questionnaires after the occurrence of a big EQ, so that some results are sometimes not so reliable. One main advantage of this paper is that the milk yield of cows has been monitored continuously for a few years at the experimental station, and the use of this kind of scientific data is extremely rare in the study of abnormal animal behavior. Yamauchi et al. (2014) [25] were the first to report on an abnormal decrease in milk yield of cows before the disastrous 2011 Tohoku EQ (Mw 9), and the main purpose of this paper is to confirm whether such an abnormal milk depression appears for another EQ or not.

The large casualty of the latest 2011 March 11 Tohoku EQ accentuated urgent necessity of short-term EQ prediction, with emphasis on further extensive studies on precursors for different EQs. After the 2011 Tohoku EQ, there have been observed a large number of EQs (or aftershocks) in the northern Japan and in the Pacific Ocean. Whereas, the western part of Japan (tentatively defined by the western part of Honshu Island, such as west of Nagoya or so) is seen to be much lower in seismic activity even after the 2011 Japan EQ, though some enhancement in seismicity was likely. As you know, we had a serious EQ in the Kobe area in 1995, for which numerous electromagnetic precursors were observed [26]. A relatively remarkable EQ with M (magnitude) greater than 6, has happened nearly at the same place as the 1995 Kobe EQ on April 12 (UT), 2013. Because EQs are extremely rare in this part of Japan, we will take this EQ as an example for our precursor case studies. There have already been reported on the precursors of seismogenic ULF (ultra low frequency) radiation [27] [28] for this EQ. So, the purpose of this paper is to report first on the abnormal animal behavior, especially the milk yield of cows as studied by Yamauchi et al. (2014) [25], at a particular place close to this EQ epicenter. Its temporal evolution has been compared with those of electromagnetic effects such as ULF radiation, ionospheric perturbations, in order to try to understand the generation mechanism of precursory depletion of milk yield of cows.

\section{The April 12, 2013 Kobe EQ}

The EQ treated here is the one occurred on April 12, 2013 (UT = 20 h 33 m) (April 13, 5 h 33 m a.m. JST), with 
$\mathrm{M}=6.3$ and depth of $15 \mathrm{~km}$. This EQ is an inland, fault-type one taken place in the land of Awaji-island, and its epicenter of this EQ is located at the geographical coordinates $\left(34^{\circ} 25.1^{\prime} \mathrm{N}, 134^{\circ} 49.7^{\prime} \mathrm{E}\right)$ as shown in Figure 1 as a blue circle. The former 1995 Kobe EQ was the consequence of movement of the Nojima fault belonging to the Rokko-Awaji fault region and the EQ in this paper is estimated to be generated at the south-west edge of aftershock region of the 1995 Kobe EQ.

After the 2011 Tohoku EQ, we notice some enhancement in seismicity in the western Japan was likely. We have examined the seismicity such as foreshocks during four months before this relevant EQ. Then it is found that no EQs happened with $M \geq 4.5$ in this district and that when lowering the threshold of $M$ down to 3.0, there happened only a small number of EQs in the south of this EQ epicenter. This might suggest that there was no clear foreshock activity before the EQ, and the April 12 Kobe EQ is likely to be an isolated EQ, so that these small EQs had no influential effect on the following milk yield of cows.

\section{Results on Milk Yield of Cows}

The data on the milk yields of cows are based on the observation at the Kagawa Prefecture Livestock Experimental Station in Shikoku Island, Japan as shown in Figure 1 as a red circle. Its location is given by the geographical coordinates $\left[34.27^{\circ} \mathrm{N}, 134.15^{\circ} \mathrm{E}\right]$, and the distance of this experimental station from the EQ epicenter is luckily only about $60 \mathrm{~km}$.

The milk yield of cows has been monitored continuously at this station, and the total milk yield of cows is recorded every day (sampling rate is 1day). This kind of digital quantitative values has never been used for the study of abnormal animal behavior. Also, cows in the experimental station are kept in a completely quiet place, being free from any disturbances.

Figure 2 illustrates the daily evolution of the milk yields of cows at Kagawa during a period from 1 March to 12 April (EQ day), 2013. The number of cows of Kagawa is smaller (on the order of 13 - 14) as compared with that [30]-[37] at Ibaraki in our previous paper [25], leading to large error bars shown in Figure 1. Because we know some known factors decreasing the mild yield, we have removed the most influential effect of the temperature and humidity [29], which is used as an index of heat stress for cows [30], by using a two-phased regression model. The final variations in Figure 1 are calculated by subtracting the average milk yield after removal of the

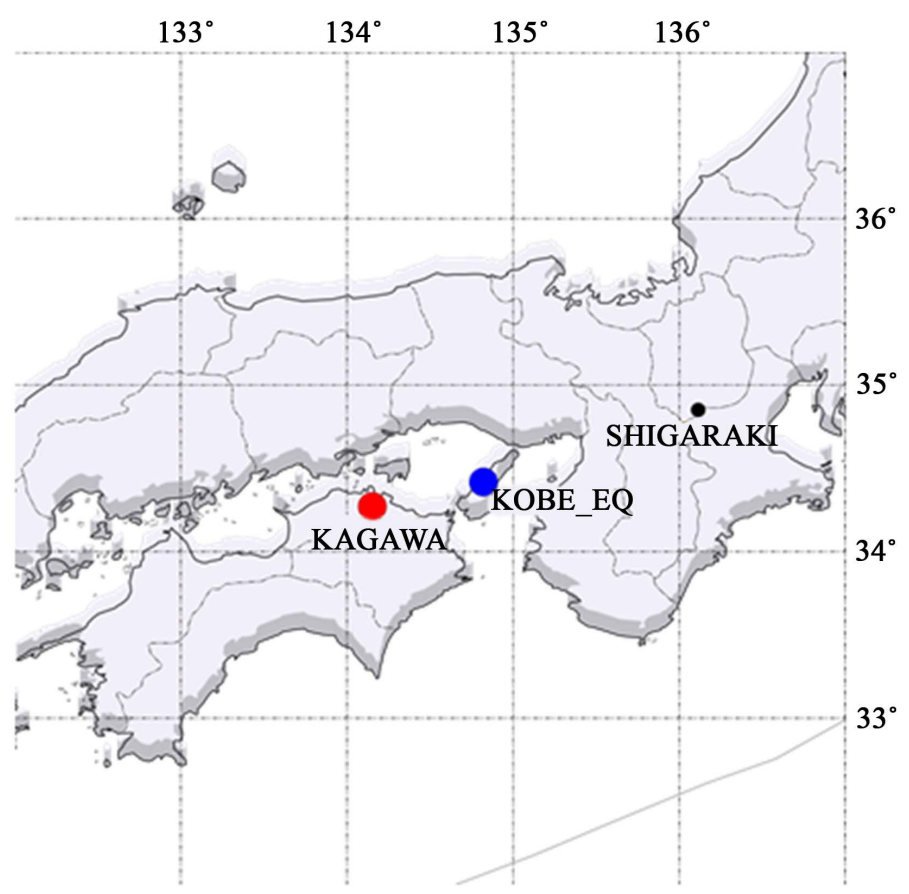

Figure 1. Relative location of the Kagawa Prefecture Livestock Experimental station (as Kagawa (red circle)), where the milk yield of cows is continuously monitored. The EQ epicenter is indicated as Kobe EQ (blue circle) in the Rokko-awaji fault. Finally, the ULF station is indicated by a small circle (Shigaraki). 


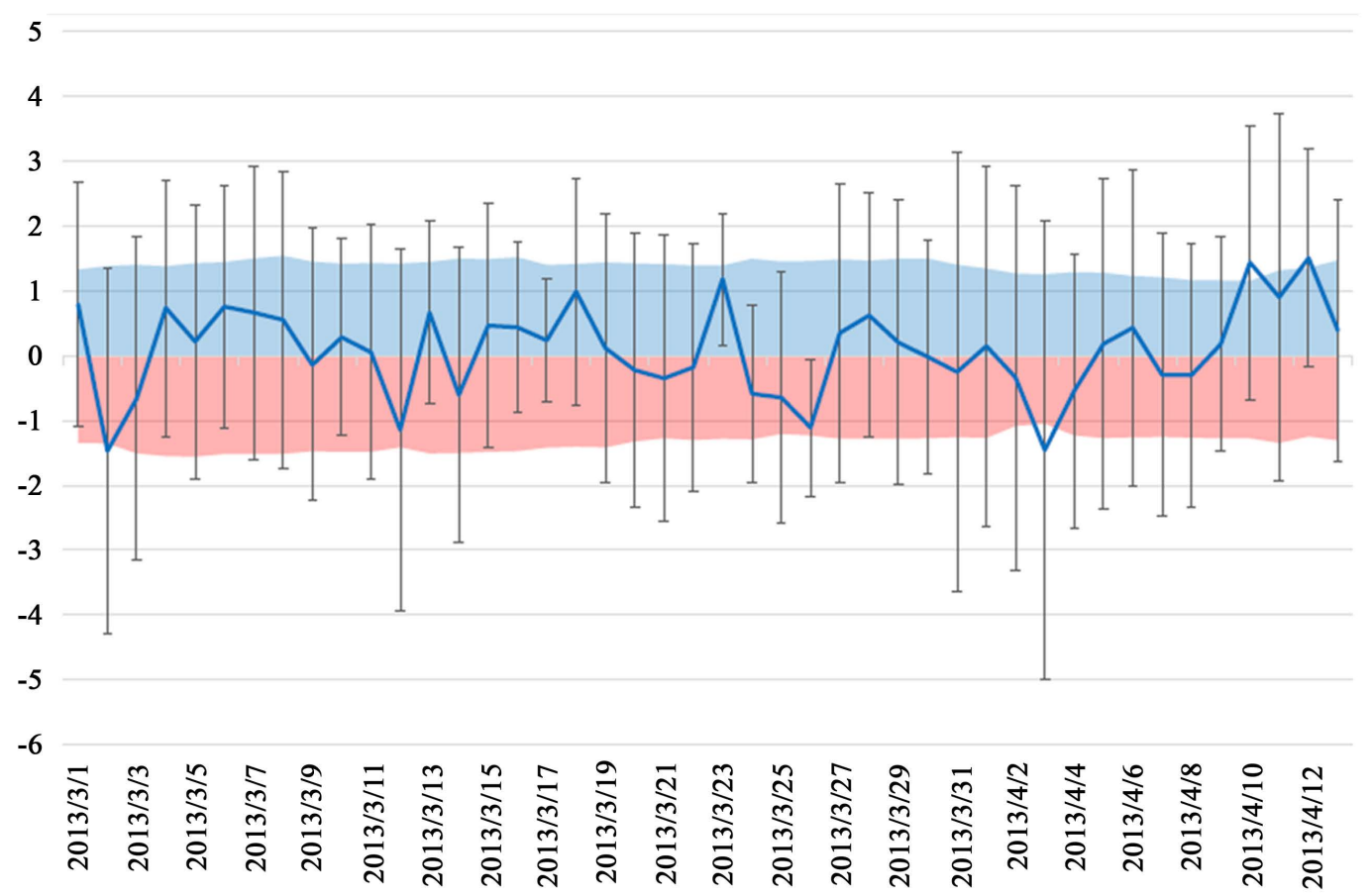

Figure 2. Daily evolution of milk yield of cows at Kagawa station in the Shikoku Island. The abscissa indicates the date, and the ordinate is the milk yield normalized by its standard deviation $(\sigma)$. The thick line is the daily average value with the corresponding error bar. The upper bound is the $+2 \sigma$ level, while the lower bound is $-2 \sigma$ level.

factors one to several days before the EQ from those of the current day. The mean value is given by the value of zero, and the conventional criteria of $+2 \sigma$ and $-2 \sigma$ ( $\sigma$ : standard deviation) are plotted in this figure. Though we have noticed two days before the EQ, on which the milk yield of cows showed unexpectedly an enhancement exceeding $+2 \sigma$, we pay particular attention to the days around April 3 with a significant depletion exceeding $-2 \sigma$ criterion, because Yamauchi et al. (2014) [25] found a significant depletion in the milk yield of cows (might be a stress to cows) before the 2011 Tohoku EQ. Even though the error bar is very large, the depletion during a few days around April 3 seems to be significant. The lead time is about 10 days, approximately in good agreement with the previous conclusion by Yamauchi et al. (2014) [25] in the case of the 2011 Tohoku EQ.

\section{Comparison with Electromagnetic Precursors}

As for electromagnetic precursors, we have already published a few papers on electromagnetic precursors to this 2013 Kobe EQ [27] [28]. Figure 3 illustrates a summary of the temporal evolutions of the abnormal animal behavior as studied in this paper, ULF radiation [27] (conventional statistical analysis), ULF radiation (non-conventional critical analysis) [28], ELF (extremely low frequency) radiation [31], ULF depression (as a signature of lower ionospheric perturbation) [32] and VLF propagation anomaly indicative of the lower ionospheric perturbation [33] [34]. In the first row, we observed the abnormal depletion of the milk yield of cows around 3 April. On the other hand, the conventional statistical analysis of ULF emissions (frequency $=0.01-0.02 \mathrm{~Hz}$ ) on the 2nd row has yielded no clear anomaly, suggesting that the seismogenic ULF emissions even if they exit, are weak in intensity. But, eventually, the non-conventional, critical analysis by means of natural time (NT) [28] (3rd row) has indicated some criticality during 27 March to 29 March for $\mathrm{F}_{\mathrm{h}}$ (horizontal magnetic field) and 27 March to 1 April for $F_{z}$ (vertical magnetic field). These results may suggest that there must have been observed rather weak ULF emissions during these time periods. The radiation in ELF on the 4th row was observed just one day before the EQ. The last two rows refer to the perturbation in the lower ionosphere. The depression of ULF horizontal magnetic field at the frequency of $0.01-0.02 \mathrm{~Hz}$ is observed on 9 April with the conventional analysis. In agreement with this ULF result, the subionospheric VLF propagation anomalies have been detected as a precursor to the 2013 Kobe EQ during a period of 6-12 April. 


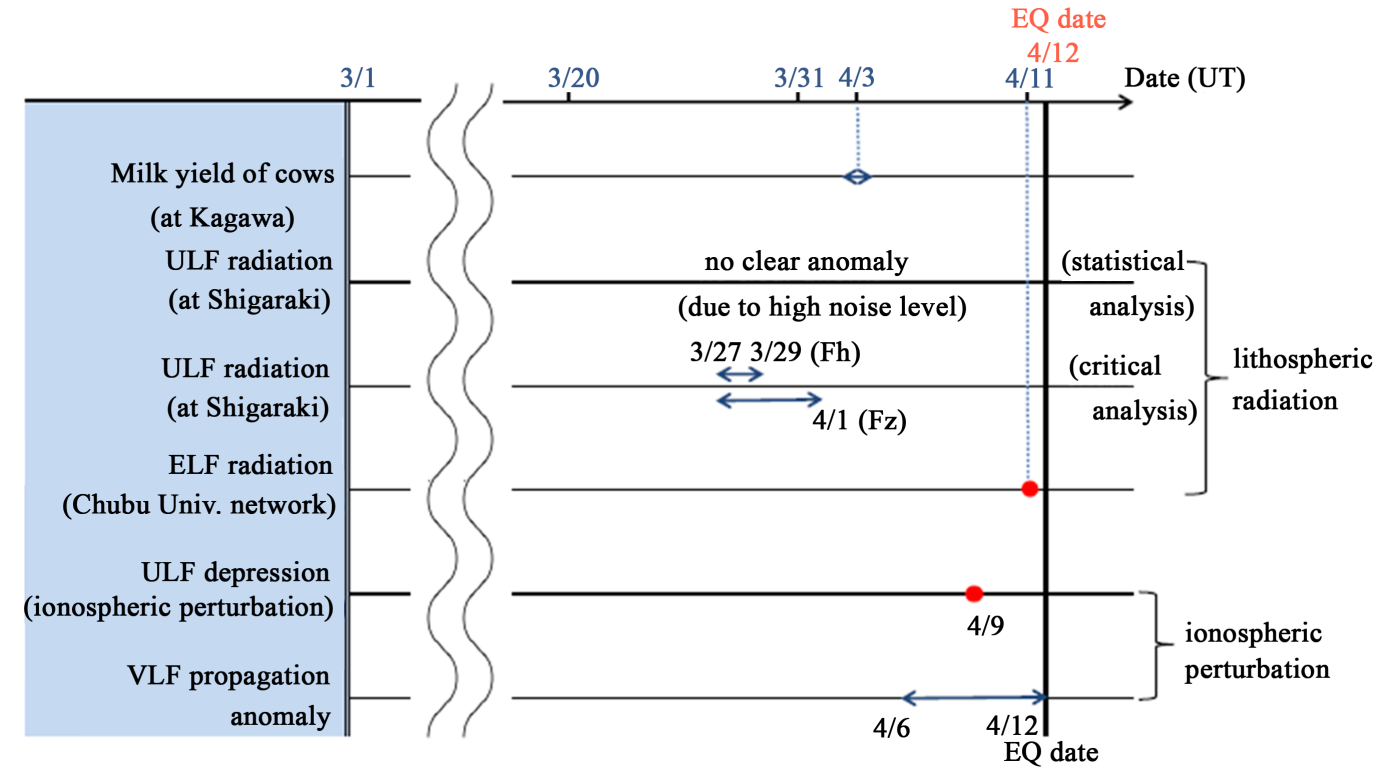

Figure 3. Summary of temporal evolutions of milk yield of cows (top row) with different electromagnetic effects (ULF radiation (conventional statistical analysis (2nd row), ULF radiation (critical analysis (3rd row), ELF radiation (4th row), ULF depression (ionospheric perturbation) (5th row) and the last column, VLF propagation anomaly).

\section{Discussion on Possible Sensory Mechanism of Abnormal Animal Behavior}

Yamauchi et al. (2014) [25] have discovered the abnormal milk yield of cows for the 2011 Tohoku EQ on the basis of its continuous monitoring, in which they have found the decrease of milk yield cows on 5, 6 March, 2011 as a precursor to the EQ. Further they have indicated that these days were coincident with those of ionospheric perturbations as detected by subionospheric VLF/LF propagation by Hayakawa et al. [32]-[34], without commenting on a possible mechanism of abnormal animal behavior. Another interesting paper has been published recently by Grant et al. (2015) [35], who have shown the unusual behavior of animals in the national park prior to a major $(\mathrm{M}=7) \mathrm{EQ}$ in the Peruvian Andes, and this abnormal animal behavior was coincident in time with the dates of ionospheric perturbation by the VLF propagation anomalies. Then, they have proposed a possible agent for both the abnormal animal behavior and ionospheric perturbation by a common effect of air ionization due to the pre-EQ generation of positive hole carriers [36].

In a famous book by Rikitake [2], he summarized possible stimuli of abnormal animal behavior, including (i) changes in air pressure, gravity and ground topography, (ii) sounds or vibrations that are accompanied by microfracture generations, (iii) changes in magnetic and electric fields, (vi) electromagnetic waves, (v) changes in underground water level, (vi) radiation of natural gas and chemical substances, and he further recommended strongly a few such as (iii), (iv) and (vi) (mainly electromagnetic effects). These effects may be major ones, but not all [16] because we need further extensive studies.

However, in complete contradiction with those synchronous temporal evolutions of abnormal animal behavior and ionospheric perturbations in the above two case studies [25] [35], Figure 3 as our summary for the precursory phenomena for the 2013 Kobe EQ, indicate a completely different view on the correlations of the abnormal animal behavior with corresponding electromagnetic signatures. Hayakawa (2013) [37] presented a hypothesis of the possible seismogenic ULF/ELF radiation as the agent for abnormal animal behavior based on the extensive comparison of the characteristics of abnormal animal behavior by Rikitake [2] with those of different electromagnetic phenomena so far reported [3]-[6]. Though the ULF (frequency $=0.01-0.02 \mathrm{~Hz}$ ) emissions are not clearly detected by the conventional statistical analysis [27], the non-conventional critical analysis based on NT analysis has yielded the criticality during 27 March to the beginning of April [28], which might indicate the generation of relatively weak seismogenic ULF emissions as compared with conspicuous high-intensity emissions for large EQs [11] [12]. And the depression of milk yield of cows was observed around 3 April, relatively close to the dates of supposed weak ULF emissions. This may suggest that ULF emission is likely to be the 
"driver" for the abnormal animal behavior, at least, for our 2013 Kobe EQ. On the other hand, the ionospheric perturbation was observed apparently later than the abnormal animal behavior; that is, on 9 April by means of ULF depression and 6-12 April by the means of subionospheric VLF propagation.

\section{Conclusions}

As a case study of the Kobe EQ on April 12, 2013, we have investigated the precursory abnormal animal behavior of milk yield of cows close to the EQ epicenter. We have found that the abnormal animal behavior (depletion in milk yield) happened about 10 days prior to the EQ. Finally, we have suggested that ULF radiation among different electromagnetic precursors is a mostly likely driver for this abnormal animal behavior.

Further extensive research based on the scientific data as in this paper is highly required, especially any statistical study on the correlation of abnormal animal behavior with EQs, and then further study on the possible stimuli of abnormal animal behavior.

\section{Acknowledgements}

The authors are grateful to the staffs of Kagawa Prefecture Livestock Experimental Station for their cooperation in this measurement. H.Y., N.O., M.O., S.T., and T.A. analyzed the animal data; A.S., J.I., S.M.P., and K.E. analyzed electromagnetic data; M.H. wrote the paper.

\section{Conflicts of Interest}

The authors declare no conflict of interest.

\section{References}

[1] Hayakawa, M. (2015) Earthquake Prediction with Radio Techniques. Wiley, NY. http://dx.doi.org/10.1002/9781118770368

[2] Rikitake, T. (2001) Predictions and Precursors of Major Earthquakes: The Science of Macro-Anomaly Precursory to an Earthquake. Terra Scientific Publishing Company, Tokyo.

[3] Molchanov, O.A. and Hayakawa, M. (2008) Seismo Electromagnetics and Related Phenomena: History and Latest Results. TERRAPUB, Tokyo.

[4] Hayakawa, M., Ed. (2009) Electromagnetic Phenomena Associated with Earthquakes. Transworld Research Network, Trivandrum.

[5] Hayakawa, M., Ed. (2012) The Frontier of Earthquake Prediction Studies. Nihon-Senmontosho-Shuppan, Tokyo.

[6] Hayakawa, M., Ed. (2013) Earthquake Prediction Studies: Seismo Electromagnetics. TERRAPUB, Tokyo.

[7] Uyeda, S., Nagao, T. and Kamogawa, M. (2009) Short-Term Earthquake Prediction: Current State of Seismo-Electromagnetics. Tectonophysics, 470, 205-213. http://dx.doi.org/10.1016/j.tecto.2008.07.019

[8] Hayakawa, M. and Hobara, Y. (2010) Current Status of Seismo-Electromagnetics for Short-Term Earthquake Prediction. Geomatics Natural Hazards \& Risk, 1, 115-155. http://dx.doi.org/10.1080/19475705.2010.486933

[9] Hayakawa, M., Kasahara, Y., Nakamura, T., Muto, F., Horie, T., Maekawa, S., Hobara, Y., Rozhnoi, A.A., Solovieva, M. and Molchanov, O.A. (2010) A Statistical Study on the Correlation between Lower Ionospheric Perturbations as Seen by Subionospheric VLF/LF Propagation and Earthquakes. Journal of Geophysical Research, 115, A09305. http://dx.doi.org/10.1029/2009ja015143

[10] Liu, J.Y. (2009) Earthquake Precursors Observed in the Ionospheric F-Region. In: Hayakawa, M., Ed., Electromagnetic Phenomena Associated with Earthquakes, Transworld Research Network, Trivandrum, 187-204.

[11] Hayakawa, M., Hattori, K. and Ohta, K. (2007) Monitoring of ULF (Ultra-Low-Frequency) Geomagnetic Variations Associated with Earthquakes. Sensors, 7, 1108-1122. http://dx.doi.org/10.3390/s7071108

[12] Hayakawa, M., Hobara, Y., Ohta, K. and Hattori, K. (2011) The Ultra-Low-Frequency Magnetic Disturbances Associated with Earthquakes. Earthquake Science, 24, 523-534. http://dx.doi.org/10.1007/s11589-011-0814-2

[13] Hattori, K. (2013) ULF Geomagnetic Changes Associated with Major Earthquakes. In: Hayakawa, M., Ed., Earthquake Prediction Studies: Seismo Electromagnetics, TERRAPUB, Tokyo, 129-152.

[14] Evernden, J. (1976) Abnormal Animal Behavior Prior to Earthquakes. U.S. Geological Survey Office of Earthquake Studies. U.S. Department of Commerce, National Technical Information Service, Alexandria.

[15] Buskirk, R.E., Frohlich, C. and Lantham, G.V. (1981) Unusual Animal Behavior before Earthquakes: A Review of 
Possible Sensory Mechanisms. Reviews of Geophysics and Space Physics, 19, 247-270. http://dx.doi.org/10.1029/RG019i002p00247

[16] Tributsch, H. (1982) When the Snakes Awake-Animals and Earthquake Prediction. MIT Press, Cambridge.

[17] Kirschvink, J.L. (2000) Earthquake Prediction by Animals: Evolution and Sensory Perception. Bulletin of the Seismological Society of America, 90, 312-323. http://dx.doi.org/10.1785/0119980114

[18] Ikeya, M. (2004) Earthquakes and Animals: From Folk Legends to Science. World Scientific, Singapore.

[19] Yokoi, S., Ikeya, M., Yagi, T. and Nagai, K. (2003) Mouse Circadian Rhythm before the Kobe Earthquake in 1995. Bioelectromagnetics, 24, 289-291. http://dx.doi.org/10.1002/bem.10108

[20] Li, Y., Liu, Y., Jiang, Z., Guan, J., Yi, G., Cheng, S., Yang, B., Fu, T. and Wang, Z. (2009) Behavioral Change Related to Wenchuan Devastating Earthquake in Mice. Bioelectromagnetics, 30, 613-620. http://dx.doi.org/10.1002/bem.20520

[21] Bhargava, N., Katiyar, V.K., Sharma, M.L. and Pradhan, P. (2009) Earthquake Prediction through Animal Behavior: A Review. Indian Journal of Biotechnology, 7-8, 159-165.

[22] Grant, R.A. and Halliday, T. (2010) Predicting the Unpredictable; Evidence of Pre-Seismic Anticipatory Behavior in the Common Toad. Journal of Zoology, 281, 263-271.

[23] Nishimura, T., Okano, H., Tada, H., Nishimura, E., Sugimoto, K., Mohri, K. and Fukushima, M. (2010) Lizards Respond to an Extremely Low-Frequency Electromagnetic Field. Journal of Experimental Biology, 213, 1985-1990. http://dx.doi.org/10.1242/jeb.031609

[24] Grant, R.A., Halliday, T., Balderer, W.P., Leuenberger, F., Newcomer, M., Cyr, G. and Freund, F.T. (2011) Ground Water Chemistry Changes before Major Earthquakes and Possible Effects on Animals. International Journal of Environmental Research and Public Health, 8, 1936-1959. http://dx.doi.org/10.3390/ijerph8061936

[25] Yamauchi, H., Uchiyama, H., Ohtani, N. and Ohta, M. (2014) Unusual Animal Behavior Preceding the 2011 Earthquake off the Pacific Coast of Tohoku, Japan: A Way to Predict the Approach of Large Earthquake. Animals, 4, 131145. http://dx.doi.org/10.3390/ani4020131

[26] Nagao, T., Enomoto, Y., Fujinawa, Y., Hata, M., Hayakawa, M., Huang, Q., Izutsu, J., Kushida, Y., Maeda, K., Oike, K., Uyeda, S. and Yoshino, T. (2002) Electromagnetic Anomalies Associated with 1995 Kobe Earthquake. Journal of Geodynamics, 33, 477-487. http://dx.doi.org/10.1016/s0264-3707(02)00004-2

[27] Schekotov, A., Izutsu, J. and Hayakawa, M. (2015) On Precursory ULF/ELF Electromagnetic Signatures for the Kobe Earthquake on April 12, 2013. Journal of Asian Earth Sciences, 114, 305-311. http://dx.doi.org/10.1016/j.jseaes.2015.02.019

[28] Potirakis, S.M., Eftaxias, K., Schekotov, A., Yamaguchi, H. and Hayakawa, M. (2016) Criticality Features in ULF Magnetic Fields Prior to the 2013 Kobe Earthquake. Annals of Geophysics, 59, S0317.

[29] National Oceanic and Atmospheric Administration (1976) Livestock Hot Weather Stress. Operations Manual Letter C-31-76, Department of Commerce, NOAA, National Weather Service Central Region, Kansas City.

[30] Vitali, A., Segnalini, M., Bertocchi, L., Bernabucci, U., Nardone, A. and Lacetera, N. (2009) Seasonal Pattern of Mortality and Relationships between Mortality and Temperature-Humidity Index in Dairy Cows. Journal of Dairy Science, 92, 3781-3790. http://dx.doi.org/10.3168/jds.2009-2127

[31] Ohta, K., Izutsu, J., Schekotov, A. and Hayakawa, M. (2013) The ULF/ELF Electromagnetic Radiation before the 11 March 2011 Japanese Earthquake. Radio Science, 48, 589-596. http://dx.doi.org/10.1002/rds.20064

[32] Hayakawa, M., Hobara, Y., Yasuda, Y., Yamaguchi, H., Ohta, K., Izutsu, J. and Nakamura, T. (2012) Possible Precursor to the March 11, 2011, Japan Earthquake: Ionospheric Perturbations as Seen by Subionospheric Very Low Frequency/Low Frequency Propagation. Annals of Geophysics, 55, 95-99.

[33] Hayakawa, M., Rozhnoi, A., Solovieva, M., Hobara, Y., Ohta, K., Schekotov, A. and Fedorov, E. (2013) The Lower Ionospheric Perturbation as a Precursor to the 11 March 2011 Japan Earthquake. Geomatics, Natural Hazards and Risk, 4, 275-287. http://dx.doi.org/10.1080/19475705.2012.751938

[34] Hayakawa, M., Hobara, Y., Rozhnoi, A., Solovieva, M., Ohta, K., Izutsu, J., Nakamura, T. and Kasahara, Y. (2013) The Ionospheric Precursor to the 2011 March 11 Earthquake Based upon Observations Obtained from the JapanPacific Subionospheric VLF/LF Network. Terrestrial, Atmospheric and Oceanic Sciences, 24, 393-408.

[35] Grant, R., Raulin, J.P. and Freund, F.T. (2015) Changes in Animal Activity Prior to a Major $(M=7)$ Earthquake in the Peruvian Andes. Physics and Chemistry of the Earth, Parts $A / B / C$, 85-86, 69-77.

[36] Freund, F.T. (2009) Stress-Activated Positive Hole Charge Carriers in Rocks and the Generation of Pre-Earthquake Signals. In: Hayakawa, M., Ed., Electromagnetic Phenomena Associated with Earthquakes, Research Signpost, India, 41-96.

[37] Hayakawa, M. (2013) Possible Electromagnetic Effects on Abnormal Animal Behavior before an Earthquake. Animals, 3, 19-32. http://dx.doi.org/10.3390/ani3010019 


\section{Submit or recommend next manuscript to SCIRP and we will provide best service for you:}

Accepting pre-submission inquiries through Email, Facebook, LinkedIn, Twitter, etc.

A wide selection of journals (inclusive of 9 subjects, more than 200 journals)

Providing 24-hour high-quality service

User-friendly online submission system

Fair and swift peer-review system

Efficient typesetting and proofreading procedure

Display of the result of downloads and visits, as well as the number of cited articles

Maximum dissemination of your research work

Submit your manuscript at: http://papersubmission.scirp.org/ 